nhân nhiều nhất ở giai đoạn II 37/61 (60,7\%) bệnh nhân, sau đó là giai đoạn III có $16 / 61$ $(26,2 \%)$ bệnh nhân và $8 / 61(13,1 \%)$ bệnh nhân ở giai đoạn IV. Nghiên cứu của Marquet năm 2008 khối u có kích thước từ 1 đến $4 \mathrm{~cm}$ chiếm $72.4 \%$, tương đương giai đoạn I và II, chỉ có $27.6 \%$ u lớn hơn $4 \mathrm{~cm}$, tương đương giai đoạn III và IV[7]. Nghiên cứu của Thankapan K năm 2011 gặp chủ yếu bệnh nhân u có kích thước từ T1 và T2 chiếm $95,8 \%[8]$. Các tác giả trên phân loại theo u theo kích thước $T$, tương đương với u có kích thức từ dưới $2 \mathrm{~cm}(\mathrm{~T} 1)$, trong khoảng 2-4 $\mathrm{cm}(\mathrm{T} 2)$ và trên $4 \mathrm{~cm}$ (T3), cách phân loại này không khác biệt nhiều so với phân loại theo giai đoạn bệnh của chúng tôi.

\section{KẾT LUÂN}

Ung thư miệng là bệnh lý phát sinh do sự biến đổi ác tính niêm mạc bao phủ trong khoang miệng với tỷ lệ mắc bệnh có chiều hướng gia tăng. Các triệu chứng lâm sàng ở giai đoạn sớm thường không được chú ý, bệnh nhân tới khám và phát hiện khi đã ở những giai đoạn muộn nêngặp nhiều khó khăn cho việc điều trị bệnh. Chỉ định điều trị ung thư miệng phụ thuộc vào giai đoạn bệnh và mức độ di căn hạch, vì vậy đối với bệnh nhân ung thư miệng cần có kế hoạch điều trị cụ thể và toàn diện cho từng bệnh nhân để có được kết quả điều trị tốt nhất.

\section{TÀI LIÊU THAM KHẢO}

1. Pablo H. Montero, Snehal G. Patel. Cancer of the oral cavity. Surg Oncol Clin N Am. 2015; 24(3):17.

2. Miranda-Filho A, Bray F. Global patterns and trends in cancers of the lip, tongue and mouth. Oral oncology. 2020 Mar;102:104551.

3. Jerjes $\mathbf{W} .$, et al., (2010). Research Clinicopathological parameters, recurrence, locoregional and distant metastasis in $115 \mathrm{~T} 1-\mathrm{T} 2$ oral squamous cell carcinoma patients. Head \& Neck Oncology 2010. 2(9): p. 21.

4. Xiao-meng Song and Jin-hai Ye, Radial forearm free flap for reconstruction of a large defect after radical ablation of carcinoma of the tongue and floor of the mouth - some new modifications. Journal for OtoRhinoLaryngology, 2010. 72: p. 7.

5. King T, Agulnik M.(2010). Head and neck cancer: Changing epidemiology and Public health implications. Oncology Journal, Vol 24,10:1-6.

6. Shah J. P. and Gil Z., Current concepts in management of oral cancer--surgery. Oral Oncology, 2009. 45(4-5): p. 394-401.

7. Faria M.J.C., et al., The versatility of the free lateral arm flap in head and neck soft tissue reconstruction: clinical experience of 210 cases. Journal of Plastic Reconstructive Aesthetic Surgery, 2008. 61(2): p. 172-179.

8. Thankappan K., et al., Lateral arm free flap for oral tongue reconstruction: an analysis of surgical details, morbidity, and functional and aesthetic outcome. Annals of Plastic Surgery, 2011. 66(3): p. 261-166.

\title{
ĐÁNH GIÁ ĐẶC ĐIỂM GIẢI PHẪU NHÁNH TRÁN ĐộNG MẠCH THÁI DƯƠ'NG NÔNG Ở NGƯỜI VIẸTT TRƯỞNG THÀNH
}

\author{
Ngô Thế Mạnh*, Vũ Ngọc Lâm**, Lê Đức Tuấn*
}

\section{TÓM TẮT}

Mục tiêu: Đánh giá đặc điểm giải phẫu nhánh trán động mạch thái dương nông (ĐMTDN) ở người Việt trưởng thành. Đối tượng và phương pháp: Mô tả cắt ngang bằng phẫu tích 31 tiêu bản nửa đâuu của 16 xác. Kết quả và kết luận: $83,8 \%$ trường hợp ĐMTDN phân nhánh tận phía trên gò má - cung tiểp. Nguyên ủy của ĐM trển hệ trục tọa độ, cách trục Ox $33,11 \pm 10,86 \mathrm{~mm}$ và cách trục Oy khoảng 16,04 \pm $8,97 \mathrm{~mm}$. Có $35,5 \%$ số trường hợp điểm này nằm trong một hình chữ nhật đứng, kích thước 20 x 30 mm. Góc TB giữa nhánh trán với ĐMTDN là 118,81 \pm

*Bệnh viện Quân y 103

**Bênh viên TUQQĐ 108

Chịu trách nhiệm chính: Ngô Thế Mạnh

Email: ntmanhdoctor@gmail.com

Ngày nhận bài: 15/10/2021

Ngày phản biện khoa học: 18/11/2021

Ngày duyệt bài: 16/12/2021
53,47 độ. Góc giữa nhánh trán và gò má cung tiếp trung bình là $40,5^{\circ}$. Chiều dài TB thân nhánh trán là $69,78 \pm 27,93 \mathrm{~mm}$. Tại nguyên ủy, nhánh trán có ĐK TB là 2,19 $\pm 0,5 \mathrm{~mm}$. Nhánh trán sau 1 xuất hiện là $96,77 \%$, nhánh trán sau 2 chiếm tỷ lệ $61,29 \%$. Nhánh trán giữa xuất hiện chiếm $80,65 \%$. Nhánh trán trước chiếm $83,87 \%$ tiêu bản. Chiêu dài trung bình của nhánh trán sau 1 , nhánh trán sau 2 , nhánh giữa và nhánh trước lần lượt là 49,39 $\pm 21,78 ; 48,42 \pm 25,92$; $40,03 \pm 21,49 ; 28,17 \pm 11,30$ mm. Góc với ĐM trán của nhánh trán sau 1 , nhánh trán sau 2 , nhánh giữa và nhánh trước lần lượt là: 80,47 \pm 23,05; 79,47 $\pm 16,49$; $112,88 \pm 43,95 ; 109,52 \pm 30,06$ độ. Nhánh trán tận hết bằng dạng I chiếm 38,7\% và dạng II 48,4\%.

Tứ khóa: Nhánh trán động mạch thái dương nông
SUMMARY
SURVEY ON ANATOMICAL CHARACTERISTICS OF THE SUPERFICIAL TEMPORAL ARTERY FRONTAL BRANCH IN ADULT VIETNAMESE
Objective: To evaluate anatomical characteristics 
of the superficial temporal artery frontal branch in adult Vietnamese. Subjects and method: Crosssectional description by dissection of 31 first half specimens of 16 corpses. Results and conclusions: $83.8 \%$ of cases of CSF branched all the way above the cheekbones - the next arc. The origin of the artery on the $\mathrm{xOy}$ coordinate system, $33.11 \pm 10.86 \mathrm{~mm}$ from the Ox axis and about $16.04 \pm 8.97 \mathrm{~mm}$ from the Oy axis. There are $35.5 \%$ of cases this point is inside a vertical rectangle, size $20 \times 30 \mathrm{~mm}$. The median angle between the frontal branch and the cerebral artery is $118.81 \pm 53.47$ degrees. The average angle between the frontal branch and the zygomatic arch is $40.5^{\circ}$. The mean length of the frontal branch body is $69.78 \pm$ $27.93 \mathrm{~mm}$. At the origin, the frontal branch has a SI of $2.19 \pm 0.5 \mathrm{~mm}$. Posterior frontal branch 1 appeared in $96.77 \%$, posterior frontal branch 2 accounted for $61.29 \%$. The middle frontal branch appeared in $80.65 \%$. The anterior frontal branch accounted for $83.87 \%$ of the specimen. The average length of posterior frontal branch 1, posterior frontal branch 2, middle branch and anterior branch is $49.39 \pm 21.78$ respectively; $48.42 \pm 25.92 ; 40.03 \pm 21.49 ; 28.17 \pm$ $11.30 \mathrm{~mm}$. Angle with frontal artery of posterior frontal branch 1, posterior frontal branch 2, middle branch and anterior branch is: $80.47 \pm 23.05$ respectively; $79.47 \pm 16.49 ; 112.88 \pm 43.95 ; 109.52$ \pm 30.06 degrees. The frontal branch is terminated mainly by type I accounting for $38.7 \%$ and type II $48.4 \%$. branch

Key word: Superficial temporal artery frontal

\section{I. ĐĂT VẤN ĐỀ}

Nhánh trán động mạch thái dương nông là một trong hai nhánh tận của ĐM TDN. Các vạt da với cuống mạch thái dương nông được ứng dụng rất nhiều trong tạo hình tổn khuyết vùng đẩu mặt. Vì lý do đó, việc hiểu động mạch thái dương nông và các nhánh của nó là rất quan trọng. Động mạch thái dương nông và các nhánh của nó cũng sử dụng như một mảnh ghép có mạch nuôi để nối mạch máu ngoài sọ và mạch máu nội so.

Trên thế giới đã có một sỗ nghiên cứu giải phẫu đã mô tả chi tiết giải phẫu nhánh trán động mạch thái dương nông và các nhánh bên của nó, tuy nhiên, các nghiên cứu nào ở Việt Nam mô tả về vấn đề này còn rất hạn chế. Các phẫu thuật viên cần phải nắm được các biến thể giải phẫu, đường đi của động mạch và các nhánh của nó để đánh giá các vấn đề về thẩm mĩ, đặc biệt là trong các phẫu thuật tạo vạt da vùng trán. Chính vì vậy, chúng tôi tiến hành nghiên cứu nhằm mục tiêu: "Đánh giá đặc điểm giải phẫu nhánh trán động mạch thái dương nông ở người Việt trưởng thành"

\section{II. ĐỐI TƯỢNG VÀ PHƯƠNG PHÁP NGHIÊN CứU}

2.1. Đối tượng nghiên cứu. Tiến hành nghiên cứu giải phẫu trên 31 mẫu tiêu bản người
Việt trưởng thành (gồm 16 xác). Mỗi tiêu bản là nửa đầu được bảo quản bằng formol $10 \%$ tại bộ môn Giải phẫu trường Đai họ $\mathrm{Y}$ khoa Pham Ngọc Thach thành phố Hồ Chí Minh và Đại học $Y$ Dược Thành phố Hồ Chí Minh.

Tất cả các tiêu bản không có vết tích bệnh lý hoặc thương tích tại vùng nghiên cứu.

2.2. Thiết kế nghiên cứu: Mô tả cắt ngang trên xác phẫu tích.

\subsection{Quy trình nghiên cứu}

*Bước 1: Xác định các mốc giải phẫu

Theo Rawlin, vẽ môt đường thằng đi từ tâm lỗ tai ngoài đến bờ dưới ổ mắt đặt tên là "đường thẳng Reid" và trục tọa độ $\mathrm{Oxy}$

+ Lấy O là tâm của lỗ tai ngoài.

+ Ox là đường thẳng chạy từ tâm điểm lỗ tai ngoài qua bờ dưới ổ mắt.

+ Oy hướng lên trên, vuông góc với Ox tại tâm lỗ tai ngoài.

*Bước 2: Bóc tách lớp da che phủ. Rạch da theo bờ trên cung mày hai bên, từ đầu ngoài cung mày kéo dài xuống dái tai hai bên. Rạch thêm một đường thẳng đứng qua chính giữa trán

Phẫu tích vùng trán bắt đầu từ chính giữa trán bóc tách sang hai bên. Bóc tách nông lớp da đầu, không làm tổn thương hệ mạch ở dưới.

*Bước 3: Phẫu tích mach máu và thân kinh. Phẫu tích mach được bắt đầu từ thân ĐM ở trước nắp tai vì ở vị trí này $Đ M$ to và dễ tìm. Sau đó bóc tách lần theo bó mạch lên trên ra dần ngoại vi cho tới khi nhánh phân chia nhỏ dần đi vào lớp bì hay nối tiếp với nhánh trán bên đối diện ở đường giữa.

* Bước 4: đo các chỉ số

+ Xác định vị trí nguyên ủy nhánh trán (phân chia nhánh tận của ĐM TDN) trên hệ trục xOy

+ Đo chiều dài nhánh trán và các nhánh tận của nó bằng thước kẹp điện tử, sai số lấy tới $0.01 \mathrm{~mm}$.

+ Đinh hướng mạch: xem góc tạo bởi thân ĐM nhánh trán với trục tọa độ, góc tạo bởi nhánh tận của thân chính ĐM nhánh trán với nhánh tận của nó bằng thước đo góc. Đo góc tạo bở thân nhánh trán ĐM TDN với gò má cung tiếp.

*Bước 5: vẽ và chụp ảnh. Vẽ đường đi của bó mạch nhánh trán TDN và các nhánh của nó lên da bằng cách xuyên kim từ dưới da lên tương ứng với đường đi của ĐM.

2.4. Xử lý số liệu: Các phân tích sẽ được thực hiện bằng phần mềm SPSS 20.0.

\section{KẾT QUẢ NGHIÊN CỨU VÀ BÀN LUẬN}

3.1. Động mạch nhánh trán

*Nguyên ủy. Trong NC của chúng tôi, 
83,8\% trường hợp ĐM TDN phân nhánh tân phía trên gò má - cung tiếp, $16,2 \%$ phân chia ngay tại gò má cung tiếp, không có trường hợp nào phân chia phía dưới gò má. Theo NC của Pinar (2006), tỷ lê này lần lượt là $74,07 \%$ và $22,22 \%$ [1]. Theo Chen (1999) NC vị trí phân chia nhánh tận của ĐM TDN ở trên - gần - dưới gò má cung tiếp lần lượt là $86,5 \% ; 3,8 \%$; và $9,6 \%$ [2]. Như vậy trong hầu hết các trường hợp, ĐM TDN phân chia nhánh tận ở phía trên gò má cung tiếp.

Nguyên ủy của ĐM trên hệ trục tọa độ xOy (được mô tả trong phần phương pháp nghiên cứu), cách trục $0 x 33,11 \pm 10,86 \mathrm{~mm}$ và cách trục Oy khoảng 16,04 $\pm 8,97 \mathrm{~mm}$. Có 35,5\% sô trường hợp điểm này nằm trong một hình chũ nhât đứng, kích thước $20 \times 30 \mathrm{~mm}$. Pham Thi Việt Dung (2017) tọa độ nguyên ủy nhánh trán là $(36,9 ; 19,8)[3]$. Theo Lee (2014) tọa độ nguyên ủy của nhánh trán là $(36,9 ; 17,2)$ [4]. Các kết quả này tương đương với kêt quả NC của chúng tôi.

* Đường đi

Bảng 3.1 Góc tạo bởi nhánh trán và thân chung DM TDN $(n=31)$

\begin{tabular}{|c|c|c|}
\hline Góc & $\mathbf{N}$ & $\mathbf{\%}$ \\
\hline Nhó $(\leq 135)$ & 15 & 48,4 \\
\hline Vừa $(136-160)$ & 11 & 35,5 \\
\hline Lớn $(161-190)$ & 5 & 16,1 \\
\hline Trung bình & $118,81 \pm 53,47$ \\
\hline
\end{tabular}

Nhánh trán chay chếch lên trên và ra trước. Lấy thân ĐM TDN làm trục, đo được góc TB giữa nhánh trán với ĐM TDN là 118,81 \pm 53,47 độ. Trong đó, phần lớn góc này dưới 135 độ, chiếm tỷ lệ 48,4\% tổng số tiêu bản. Theo Phạm Thị Việt Dung (2017) thì góc này trung bình là 130 độ, cao hơn so với NC của chúng tôi[3].

* Góc tao bởi nhánh trán ĐM TDN và gò má cung tiếp. Trong NC của chúng tôi, góc giữa nhánh trán và gò má cung tiếp trung bình là $40,5^{\circ}$. Kết quả này tương đương với NC của tác giả Mateusz (2019) đề xuất đo góc giữa nhánh trán và một mốc xác định trước là gò má cung tiếp. Góc này trung bình là $43,2 \pm 12,2^{\circ}$.

*Chiêu dài. Chiều dài thân nhánh trán được tính từ nguyên ủy đến điểm chia nhánh tân của nó. Chiều dài TB của thân nhánh trán là $69,78 \pm$ 27,93 mm. Theo Phạm Thị Việt Dung (2017), chiều dài này là $59 \pm 35 \mathrm{~mm}[3]$. Theo số liệu của Taolei (2005) trên 25 tiêu bản, chiều dài thân nhánh trán trung bình là $56 \pm 12 \mathrm{~mm}$ [5]. Các kết quả này đều cao hơn so với NC của chúng tôi. Sự thay đổi chiều dài cuống mạch phụ thuộc vào một số yếu tố sau: nếu ĐM TDN chia nhánh tận sớm hơn so với mức trung bình, nguyên ủy của nhánh trán sẽ ở thấp thì thân chung ĐM sẽ dài hơn và ngược lại.

*Đường kính. Tai nguyên ủy, nhánh trán có ĐK TB là 2,19 $\pm 0,5 \mathrm{~mm}$. Theo Pham Thi Viêt Dung (2017), nguyên ủy nhánh trán có ĐK TB là $1,51 \pm 0,32 \mathrm{~mm}[3]$. Yelda (2006) nghiên cứu trên 14 xác, kết luận đường kính trung bình nhánh trán là 2,14 $\pm 0,54 \mathrm{~mm}$ [1]. Như vậy, đường kính trung bình trong $\mathrm{NC}$ của chúng tôi cao hơn so với các tác giả khác. Nhìn chung, đường kính nguyên ủy nhánh trán khá lớn (trên $1 \mathrm{~mm}$ ), đảm bảo nguồn cấp máu cho vùng trán.

3.2 Các nhánh tận của nhánh trán ĐM TDN

* Các nhánh tận của nhánh trán động mạch thái dương nông

Bảng 3.2 Đặc điểm các nhánh tận của động mạch trán $(n=31)$

\begin{tabular}{|c|c|c|c|c|}
\hline Chỉ số & Nhánh sau 1 & Nhánh sau 2 & Nhánh giữa & Nhánh trước \\
\hline Số tiêu bản có & 30 & 19 & 25 & 25 \\
\hline Chiều dài TB & $49,39 \pm 21,78$ & $48,42 \pm 25,92$ & $40,03 \pm 21,49$ & $28,17 \pm 11,30$ \\
\hline Góc với ĐM trán & $80,47 \pm 23,05$ & $79,47 \pm 16,49$ & $112,88 \pm 43,95$ & $109,52 \pm 30,06$ \\
\hline
\end{tabular}

Nhân xét:

*Nhánh trán sau 1. ĐM này tương đối hằng đinh, luôn có mắt 30/31 tiêu bản, chiêu dài trung bình là 49,39 $\pm 21,78 \mathrm{~mm}$. Đặc biệt hơn, hướng đi của nhánh trán sau 1 gần như vuông góc với thân nhánh trán, góc TB giữa nhánh trán sau 1 và thân chính ĐM nhánh trán là $80,47 \pm 23,05$ độ. Kết quả này tương đương với Phạm Thị Việt Dung (2017)[3].

Nhánh trán sau 1 đi thẳng lên trên, ra sau vùng đỉnh. Trong đa số các tiêu bản chúng tôi ghi nhân được sự tiếp nối giữa 2 nhánh trán sau 1 ở giữa đỉnh. Hình thái tiếp nối cùng bên hay đối bên này đã được mô tả bởi Abul Hassan [6].

Theo Phạm Thị Việt Dung (2017), ĐK nguyên ủy nhánh trán sau 1 có kích thước TB là $1,1 \pm$ $0,3 \mathrm{~mm}[3]$.

*Nhánh trán sau 2. Gặp ở 19/31 tiêu bản, chiếm tỷ lệ $61,3 \%$, là nhánh có tân suất xuất hiện thấp nhất trong 4 nhánh tận. Tỷ lệ gặp trong NC của chúng tôi cao hơn so với các tác giả Phạm Thị Việt Dung (2017). Góc giữa nhánh trán sau 2 với thân nhánh trán ĐM TDN là 79,47 $\pm 16,49$ độ. Chiều dài nhánh trán sau 2 trung bình là 48,42 $\pm \mathbf{2 5 , 9 2} \mathrm{mm}$, ĐM có đường đi song song với nhánh trán sau 1 , sau khi tách 
khỏi nhánh trán ĐM TDN, ĐM chạy lên trên và ra sau vùng đỉnh.

*Nhán trán giữa. Nhánh trán giữa xuất hiện ở 25/31 tiêu bản và tạo với thân nhánh trán một góc trung bình $112,88 \pm 43,95$ độ. Chiêu dài trung bình nhánh trán giữa là 40,03 $\pm 21,49$ $\mathrm{mm}$. Sau khi chạy thẳng ra phía trước trán ĐM thường phân ra một nhánh lớn có xu hướng chạy chếch lên trên đường giữa và tận cùng ở đường chân tóc.

\section{*Nhánh trán trước}

Tần suất xuất hiên nhánh trán trước trong nghiên cứu là 25/31 tiêu bản, là nhánh tận dưới cùng của nhánh trán, đi hơi chếch xuống dưới tạo một góc trung bình là 109,52 \pm 30,06 độ so với nhánh trán sau.

Trên lâm sàng, ứng dụng đặc điểm nhánh trán chia làm 3 nhánh tận, để phục hồi khuyết phần mềm góc mắt ngoàii, Cologlu [7] sử dụng vạt đảo 2 thùy dựa trên 2 trong 3 nhánh tận của nhánh trán tạo hình góc ngoài mi trên và mi dưới. Vạt có hình giống hoa Tulip.

* Các dạng chia nhánh tận của nhánh trán

Bảng 3.3. Các dạng chia nhánh tận của nhánh trán $(n=31)$

\begin{tabular}{|c|c|c|c|c|}
\hline $\begin{array}{c}\text { Dạng chia } \\
\text { nhánh tận }\end{array}$ & $\begin{array}{c}\text { Dạng } \\
\text { I }\end{array}$ & $\begin{array}{c}\text { Dạng } \\
\text { II }\end{array}$ & $\begin{array}{c}\text { Dạng } \\
\text { III }\end{array}$ & Dạng IV \\
\hline Số tiêu bản $(\mathrm{n})$ & 12 & 15 & 3 & 1 \\
\hline Tỉ lệ (\%) & 38,7 & 48,4 & 9,7 & 3,2 \\
\hline
\end{tabular}

Nhận xét: Nhánh trán tận hết bằng $1,2,3$ hay 4 nhánh theo các dang sau:

Dạng I: nhánh trán chia làm 4 nhánh tận gồm có: nhánh trán sau 1, nhánh trán sau 2, nhánh trán giữa và nhánh trán trước.

Dang II: nhánh trán chia 3 nhánh tận là nhánh trán trước, giữa và nhánh trán sau.

Dạng III: nhánh trán chia làm 2 nhánh tận

Dạng IV: nhánh trán tận hết bằng 1 nhánh trán trước
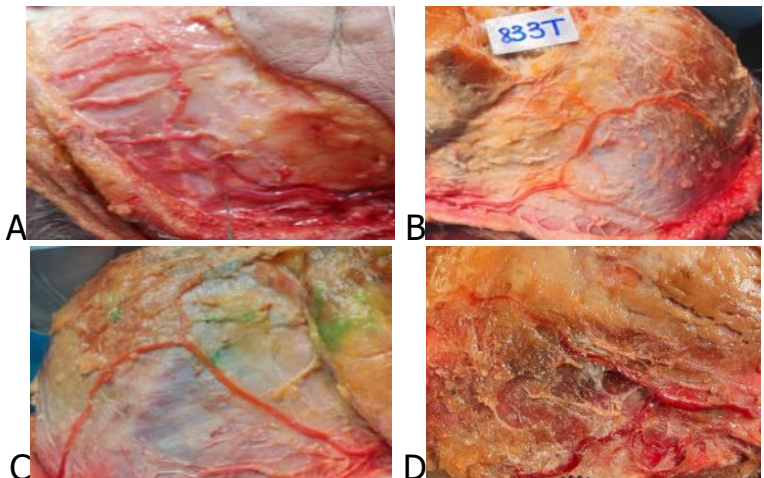

A: 4 nhánh tận (mã số xác:308 trái )

B: 3 nhánh tận (mã số xác: 833.1 trái)

C: 2 nhánh tận (mã số xác:833.1 phải);
D: 1 nhánh tận (mã số xác: 813 phải)

\section{Hình 3.1. Các dạng chia nhánh tận của} nhánh trán

Trong nhóm NC, dạng 2 chiểm tỷ lệ cao nhất $48,4 \%$, dạng 4 chiếm tỷ lệ ít nhất với 3,2\%. Trong các tài liệu giải phẫu cũng như ứng dụng của nhánh trán ĐM TDN, chỉ có một vài tác giả đề cập đến việc phân chia các nhánh tận của nhánh trán như Cologlu (2007) [7], Ozdemir (2002) [8]. Tuy nhiên không thây tác giả nào đề cập đến nhánh trán sau thứ 2 .

\section{KẾT LUẬN}

- 83,8\% trường hợp ĐM TDN phân nhánh tận phía trên gò má - cung tiếp. Nguyên ủy của ĐM trên hệ trục tọa độ xOy cách trục Ox 33,11 \pm $10,86 \mathrm{~mm}$ và cách trục Oy khoảng 16,04 $\pm 8,97$ $\mathrm{mm}$. Có $35,5 \%$ số trường hợp điểm này nằm trong một hình chữ nhật đứng, kích thước 20 x 30 mm.

- Góc TB giữa nhánh trán với ĐM TDN là $118,81 \pm 53,47$ độ. Góc giữa nhánh trán và gò má cung tiếp trung bình là $40,5^{\circ}$. Chiều dài TB của thân nhánh trán là $69,78 \pm 27,93 \mathrm{~mm}$. Tại nguyên ủy, nhánh trán có ĐK TB là 2,19 $\pm 0,5 \mathrm{~mm}$.

- Nhánh trán sau 1 xuất hiện là $96,77 \%$, nhánh trán sau 2 chiếm tỳ lệ $61,29 \%$. Nhánh trán giữa xuất hiện chiếm $80,65 \%$. Nhánh trán trước chiếm $83,87 \%$ tiêu bản. Chiều dài trung bình của nhánh trán sau 1, nhánh trán sau 2, nhánh giữa và nhánh trước lần lượt là 49,39 \pm 21,$78 ; 48,42 \pm 25,92 ; 40,03 \pm 21,49 ; 28,17 \pm$ $11,30 \mathrm{~mm}$. Góc với ĐM trán của nhánh trán sau 1 , nhánh trán sau 2 , nhánh giữa và nhánh trước lần lượt là: $80,47 \pm 23,05 ; 79,47 \pm 16,49$; $112,88 \pm 43,95 ; 109,52 \pm 30,06$ độ. Nhánh trán tận hết chủ yếu bằng dạng $\mathrm{I}$ chiểm $38,7 \%$ và dạng II 48,4\%.

\section{TÀI LIỆU THAM KHẢO}

1. Y. A. Pinar,F. Govsa (2006), "Anatomy of the superficial temporal artery and its branches: its importance for surgery". Surg Radiol Anat, 28(3), pp. 248-53.

2. T. H. Chen, C. H. Chen, J. F. Shyu. et al.(1999), "Distribution of the superficial temporal artery in the Chinese adult". Plast Reconstr Surg, 104(5), pp. 1276-9.

3. Phạm Thị Việt Dung (2017). Nghiên cứu giải phẩu và ứng dựng hệ mạch thái dương nông trong phẫu thuật tạo hình. Đại học Y Hà Nội.

4. J. G. Lee, H. M. Yang, K. S. Hu. et al.(2015), "Frontal branch of the superficial temporal artery: anatomical study and clinical implications regarding injectable treatments". Surg Radiol Anat, 37(1), pp. 61-8.

5. Tao Lei, Da-Chuan $\mathrm{Xu}$, Jian-Hua Gao. et al.(2005), "Using the frontal branch of the superficial temporal artery as a landmark for 
locating the course of the temporal branch of the facial nerve during rhytidectomy: an anatomical study". Plastic reconstructive surgery, 116(2), pp. 623-629.

6. Hussein S Abul-Hassan, Grace von Drasek Ascher,Robert D Acland (1986), "Surgical anatomy and blood supply of the fascial layers of the temporal region". Plastic reconstructive surgery, 77(1), pp. 17-28.

7. Harun Cöloglu, Ugur Koçer, Melike Oruç. et al. (2007), "Axial bilobed superficial temporal artery island flap (tulip flap): reconstruction of combined defects of the lateral canthus including the lower and upper eyelids". Plastic reconstructive surgery, 119(7), pp. 2080-2087.

8. Ragip Ozdemir, Nezih Sungur, Omer Sensöz. et al. (2002), "Reconstruction of facial defects with superficial temporal artery island flaps: a donor site with various alternatives". Plastic reconstructive surgery, 109(5), pp. 1528-1535.

\section{ĐẶC ĐIỂM LÂM SÀNG, HİNH ẢNH SIÊU ÂM CỦA BỆNH NHÂN Có HộI CHỨNG ỐNG CỔ TAY}

\section{Trần Thị Lan ${ }^{1}$, Lưu Thị Bình ${ }^{1}$, Nguyễn Trường Giang ${ }^{2}$}

\section{TÓM TẮT}

Mục tiêu: Mô tả đăc điểm lâm sàng, hình ảnh siêu âm khớp cổ taycủa các bệnh nhân có hội chứng ống cổ tay điều trị tại bệnh viện Trung ương Thái Nguyên. Đối tượng và phương pháp: Mô tả cắt ngang 36 bênh nhân có 49 ống cổ tay được chẩn đoánxác định hội chứng ống cổ tay theo tiêu chuẩn củaviện quốc gia Hoa Kỳ về sức khỏe và an toàn nghề nghiêp năm1993. Kết quả: Tỷ lệ bệnh nhân nữ/nam=8/1. Tuổi trung bình là $54,4 \pm 12,1$. Triệu chứnglâm sàng của tay bị bệnh: $98 \%$ có tê bì, $87,8 \%$ có đau dọc theo chi phố của dây thần kinh, $75,5 \%$ có di cảm cả ngày lẫn đêm, $79,6 \%$ giảm hoăc mất cảm giác các ngón tay III, IV, V,. Phân độ lâm sàng: 48,9\% ống cổ tay bệnh ở giai đoan trung bình, $32,7 \%$ ở giai đoạn nặng. Tỷ lệ nghiệm pháp Phalen (+) là $87,8 \%$ số ống cổ tay, dấu hiệu Tinel $(+)$ là $63,3 \%$, nghiệm pháp Ducan $(+)$ là $53,1 \%$. Có $57,1 \%$ ống cổ tay có dấu hiệu Notch $(+)$, dấu hiêuu Notch đảo ngược $(+)$ ở $4,1 \%$ ống cổ tay. Dấu hiệu tăng sinh mạch gặp ở $55,1 \%$ ống cổ tay. Diên tích dây thần kinh giữa đâu gần ống cổ tay trung bình $11,1 \pm 1,9$ ở bên tay thuận và $11,7 \pm 1,4$ ở bên không thuận. Kết luận: Triệu chứng lâm sàng thường gặp của hội chứng ống cổ tay là các biểu hiện tổn thương của dây thần kinh giữa. Siêu âm giúp chẩn đoán xác định hội chứng ống cổ tay qua biểu hiện tăng sinh mạch trong dây thần kinh, dấu hiệu Notchs, diện tích dây thần kinh giữa đâuu gần ống cổ tay tăng.

Từ khóa: Hội chứng ống cổ tay, đặc điểm lâm sàng, siêu âm Doppler năng lượng

\section{SUMMARY}

\section{CLINICAL CHARACTERISTICS, IMAGES OF ULTRASOUND OF PATIENTS WITH CARPAL TUNNEL SYNDROME}

\footnotetext{
${ }^{1}$ Trường ĐH Y Dược, Đại học Thái Nguyên

²Bệnh viện Trung Ương Thái Nguyên

Chịu trách nhiệm chính: Lưu Thị Bình

Email: Luuthibinh@tump.edu.vn

Ngày nhận bài: 13/11/2021

Ngày phản biên khoa họ: 14/12/2021

Ngày duyệt bài: 22/12/2021
}

Aim: Description of the clinical characteristics and images of power Doppler ultrasound of patients with carpal tunnel syndrome treated at Thai Nguyen National Hospital. Subjects and methods: Crosssectional description of 36 patients with 49 carpal tunnels diagnosed with carpal tunnel syndrome according to National Institute for Occupational Safety and Health in 1993 from July 2020 to July 2021. Result: Female/male ratio $=8 / 1$. The mean age of the patients was $54,4 \pm 12$. Clinical symptoms of the patients was: $98,0 \%$ of numbness, $87,8 \%$ with pain along the median nerve, $75,5 \%$ of paresthesia during day and night, $79,6 \%$ of decreased or lostsensation in the finger III, IV, V. Phalen test $(+)$ was found in $87,8 \%$ of carpal tunnels, Tinel sign $(+)$ in $63,3 \%$ of the ones, Ducan test $(+)$ in $53,1 \%$ of the ones. There was $57,1 \%$ of the carpal tunnels with Notch sign $(+)$, reversed Notch sign $(+)$ in $4.1 \%$ of the carpal tunnels. Signs of angiogenesis were found in $55,1 \%$ of the carpal tunnel. The median nerve area proximal to the carpal tunnel averaged $11,1 \pm 1,9$ on the preferred hand and $11,7 \pm 1,4$ on the other hand. Conclusion: The most common clinical symptoms of carpal tunnel syndrome were the result of the damaged median nerve. Ultrasound helps to confirm the diagnosis of carpal tunnel syndrome by showing increased angiogenesis in the nerve, Notchs sign, and increased area of the median nerve near the carpal tunnel.

Keywords: Carpal tunnel syndrome, clinical characteristics, power Doppler ultrasound

\section{I. ĐĂT VẤN ĐỀ}

Hội chứng ống cổ tay (Carpal tunnel syndrome) là bệnh lý rất thường gặp, do dây thân kinh giữa trong ống cổ tay khi bị chèn ép và gây ra một loạt các triệu chứng như đau, tê bì, dị cảm, giảm hoặc mất cảm giác gây hạn chế vận động ngón cái, teo cơ ô mô cái[7]. Hội chứng ống cổ tay tuy không gây tử vong nhưng ảnh hưởng lớn đến chất lượng cuộc sông bệnh nhân. Trước đây, chẩn đoán hội chứng ống cổ tay chủ yếu dựa vào lâm sàng. Các test khám thường được ứng dụng trong chẩn đoán bệnh 